\title{
(2) \\ Mammalian cell growth versus biofilm formation on biomaterial surfaces in an in vitro post-operative contamination model
}

Correspondence

Henny C. van der Mei

h.c.van.der.mei@med.umcg.nl

Received 12 April 2010

Revised 1 June 2010

Accepted 28 June 2010

\author{
Guruprakash Subbiahdoss, Roel Kuijer, Henk J. Busscher \\ and Henny C. van der Mei
}
Department of Biomedical Engineering, University Medical Center Groningen and University of Groningen, PO Box 196, 9700 AD Groningen, The Netherlands

\begin{abstract}
Biomaterial-associated infections are the major cause of implant failure and can develop many years after implantation. Success or failure of an implant depends on the balance between host tissue integration and bacterial colonization. Here, we describe a new in vitro model for the postoperative bacterial contamination of implant surfaces and investigate the effects of contamination on the balance between mammalian cell growth and bacterial biofilm formation. U2OS osteosarcoma cells were seeded on poly (methyl methacrylate) in different densities and allowed to grow for $24 \mathrm{~h}$ in a parallel-plate flow chamber at a low shear rate $\left(0.14 \mathrm{~s}^{-1}\right)$, followed by contamination with Staphylococcus epidermidis ATCC 35983 at a shear rate of $11 \mathrm{~s}^{-1}$. The U2OS cells and staphylococci were allowed to grow simultaneously for another $24 \mathrm{~h}$ under lowshear conditions $\left(0.14 \mathrm{~s}^{-1}\right)$. Mammalian cell growth was severely impaired when the bacteria were introduced to surfaces with a low initial cell density $\left(2.5 \times 10^{4} \mathrm{cells}^{-2}\right)$, but in the presence of higher initial cell densities $\left(8.2 \times 10^{4}\right.$ cells $\mathrm{cm}^{-2}$ and $17 \times 10^{4}$ cells $\left.\mathrm{cm}^{-2}\right)$, contaminating staphylococci did not affect cell growth. This study is believed to be the first to show that a critical coverage by mammalian cells is needed to effectively protect a biomaterial implant against contaminating bacteria.
\end{abstract}

\section{INTRODUCTION}

Biomaterial-associated infections (BAI) can develop from the peri-operative microbial contamination of implant surfaces during implantation, immediately post-surgery during hospitalization or by late haematogenous spreading from infections elsewhere in the body. Both peri-operative and post-operative contamination can cause BAI long after implantation, as bacteria can stay dormant on an implant surface for several years (Singh et al., 2009; Proctor et al., 2006). Micro-organisms involved in BAI are resistant to antibiotics and the host immune system due to their biofilm mode of growth, and biomaterial implants with a biofilm have to be removed in most cases (Gristina et al., 1976, 1990; Habash \& Reid, 1999). Irrespective of the route of infection, the fate of a biomaterial implant depends mainly on the outcome of the so-called 'race for the surface' between successful tissue integration of the biomaterial implant and biofilm growth (Gristina, 1987). If this race is won by tissue cells, then the biomaterial surface is fully integrated by tissue cells and less vulnerable to bacterial biofilms. On the other hand, if the race is won by

Abbreviations: BAl, biomaterial-associated infections; CLSM, confocal laser scanning microscopy; PMMA, poly(methyl methacrylate); TRITC, tetramethylrhodamine isothiocyanate. bacteria, the implant surface becomes colonized by bacteria and tissue cell functions are hampered by bacterial virulence factors and toxins (Gristina, 1987; Gristina et al., 1988). In the concept of the race for the surface, a full surface coverage of a biomaterial in vivo by a viable tissue cell layer, an intact cell membrane and functional host defence mechanisms resist bacterial colonization (Gristina, 1994).

Previously an in vitro experimental model for the perioperative bacterial contamination of implant surfaces was put forward and the effects of bacterial presence on the adhesion, spreading and growth of mammalian cells were determined in a single experiment (Subbiahdoss et al., 2009). The outcome of the race for the surface between contaminating Staphylococcus epidermidis and mammalian cells on glass appeared to be dependent on the number of bacteria present prior to mammalian cell seeding and the absence or presence of fluid flow. The mammalian cells lost the race for the surface in the absence of flow due to the accumulation of bacterial toxins, but were able to grow under flow conditions due to the continuous supply of fresh medium to, and removal of endotoxins from, the interface on all commonly used biomaterial surfaces (Subbiahdoss et al., 2010). 
In the concept of the race for the surface, as proposed by the late orthopaedic surgeon A. G. Gristina, tissue integration is an important protective factor against bacterial contamination of an implant surface (Gristina, 1994). However, the degree of tissue coverage required to effectively protect an implant surface against bacterial contamination is unknown due to lack of a suitable experimental model. Here we describe an in vitro model for postoperative bacterial contamination of implant surfaces and investigate how different degrees of mammalian cell coverage affect the balance between cell growth and bacterial biofilm formation.

\section{METHODS}

Biomaterial surface. Poly(methyl methacrylate) (PMMA) (Vink Kunststoffen), a commonly used biomaterial, was used as a substratum surface. Samples were rinsed thoroughly with ethanol and washed with sterile ultrapure water before use.

Mammalian cell culturing and harvesting. U2OS osteosarcoma cells were routinely cultured in Dulbecco's Modified Eagle's medium (DMEM), low-glucose supplemented with $10 \%$ fetal bovine serum (FBS) and $0.2 \mathrm{mM}$ ascorbic acid-2-phosphate (AA2P) and denoted as 'DMEM + FBS'. Cells were maintained at $37^{\circ} \mathrm{C}$ in a humidified atmosphere with $5 \% \mathrm{CO}_{2}$ and passaged at $70-90 \%$ confluence using trypsin/EDTA.

Bacterial growth conditions and harvesting. S. epidermidis ATCC 35983 , originally isolated from the blood of a human patient with an infected intravascular catheter, was used throughout this study. First, the strain, taken from a frozen stock, was streaked on a blood agar plate and grown overnight at $37^{\circ} \mathrm{C}$. The plate was then kept at $4{ }^{\circ} \mathrm{C}$. For each experiment, a colony was inoculated in $10 \mathrm{ml}$ tryptone soya broth (TSB; Oxoid) and cultured for $24 \mathrm{~h}$. This culture was used to inoculate a second culture, which was grown for $17 \mathrm{~h}$ prior to harvesting. Bacteria were harvested by centrifugation at $5000 \mathrm{~g}$ for $5 \mathrm{~min}$ at $10^{\circ} \mathrm{C}$ and washed twice with sterile ultrapure water. Subsequently, the harvested bacteria were sonicated $(3 \times 10 \mathrm{~s})$ in sterile PBS on ice in order to break up bacterial aggregates. This suspension was further diluted in sterile PBS to a concentration of $3 \times 10^{6}$ bacteria $\mathrm{ml}^{-1}$.

Competitive assay for mammalian cell growth and bacterial biofilm formation. The competitive assay was studied on the PMMA bottom plate of a parallel-plate flow chamber (channel dimensions $175 \times 17 \times 0.75 \mathrm{~mm})$, as described in detail by Subbiahdoss et al. (2009). The flow chamber, equipped with heating elements, was kept at $37^{\circ} \mathrm{C}$ throughout the experiments. Bacterial and U2OS cell deposition were observed with a CCD camera (Basler AG) mounted on a phase-contrast microscope (Olympus $\mathrm{BH}-2$ ) with a $40 \times$ objective, for observing bacteria, and a $10 \times$ objective, for observing mammalian cells.

Prior to each experiment, all tubes and the flow chamber were filled with sterile PBS, taking care to remove all air bubbles from the system. Once the system was filled, PBS was allowed to flow through the system at a shear rate of $11 \mathrm{~s}^{-1}$. Then, the U2OS cell suspension in modified culture medium, consisting of $98 \%$ DMEM + FBS and $2 \%$ TSB, suitable for the simultaneous growth of U2OS cells and $S$. epidermidis (Subbiahdoss et al., 2009), was allowed to enter the flow chamber. Once the entire volume of buffer inside the chamber had been replaced by the U2OS cell suspension, the flow was stopped for $1.5 \mathrm{~h}$ in order to allow cells to adhere to and spread across the substratum. Subsequently, phase-contrast images (nine images, $900 \times 700 \mu \mathrm{m}$ each) were taken and the number of adhering cells per unit area and the area per spread cell were determined using Scion image software. Subsequently, modified culture medium supplemented with $2 \%$ HEPES was perfused through the system at a low shear rate of $0.14 \mathrm{~s}^{-1}$ for $24 \mathrm{~h}$. Experiments with three different U2OS cell densities $\left(1.2 \times 10^{5}\right.$ cells ml $^{-1}, 6 \times 10^{5}$ cells ml ${ }^{-1}$ and $13 \times 10^{5}$ cells $\mathrm{ml}^{-1}$ ) were performed to attain different degrees of initial cell coverage after $24 \mathrm{~h}$, prior to seeding with bacteria. After $24 \mathrm{~h}$ U2OS cell growth, the bacterial suspension in PBS was perfused through the chamber at shear rate of $11 \mathrm{~s}^{-1}$ and phase-contrast images were obtained as a function of time. As soon as the desired density of adhering bacteria $\left(10^{3}\right.$ cells $\mathrm{cm}^{-2}$, which is a relevant number in implant contamination: Kadurugamuwa et al., 2003) was reached (after $\sim 20 \mathrm{~min}$ ), the flow was switched to sterile PBS to remove unattached bacteria from the tubes and flow chamber, after which modified culture medium supplemented with $2 \%$ HEPES was perfused through the system at a low shear rate of $0.14 \mathrm{~s}^{-1}$ for another $24 \mathrm{~h}$. HEPES was added in order to compensate for the absence of $5 \% \mathrm{CO}_{2}$ during cell growth in the flow chamber.

Immuno-cytochemical staining and determination of U2OS cell surface coverage. After simultaneous growth of bacteria and U2OS cells, surfaces were prepared for immuno-cytochemical staining to assess the morphology and spreading of the mammalian cells. For fixation, surfaces with adhering bacteria and U2OS cells were placed in a Petri dish with $30 \mathrm{ml}$ of $3.7 \%$ formaldehyde in cytoskeleton stabilizing buffer (CS; 0.1 M PIPES, $1 \mathrm{mM}$ EGTA, 4\% (w/v) polyethylene glycol 8000; $\mathrm{pH}$ 6.9). After $5 \mathrm{~min}$, the fixation solution was replaced by $30 \mathrm{ml}$ fresh CS for another $5 \mathrm{~min}$. Subsequently the cell mixture was incubated in $0.5 \%$ Triton X-100 for 3 min, rinsed with PBS and stained for $30 \mathrm{~min}$ with $5 \mathrm{ml}$ PBS containing $49 \mu \mathrm{l}$ DAPI and $2 \mu \mathrm{g} \mathrm{ml}^{-1}$ of TRITC-phalloidin. The cells on the surfaces were washed four times in PBS and examined by confocal laser scanning microscopy (CLSM; Leica DMRXE with confocal TCS SP2 unit). Images (nine images on different locations, $900 \times 700 \mu \mathrm{m}$ each) were taken and the number of adhering cells per unit area and the mean area per spread cell were determined using Scion image software to yield the total coverage area of the substratum surface by mammalian cells.

Statistics. Data are presented as mean \pm SD of nine images. Statistical ANOVA analysis was performed followed by a Tukey's HSD post-hoc test and a $P$-value of $<0.05$ was considered significant.

\section{RESULTS}

U2OS cells were allowed to adhere and spread for $24 \mathrm{~h}$ prior to S. epidermidis adhesion to mimic post-operative infection. Subsequently, the simultaneous growth of mammalian and S. epidermidis cells was observed for $24 \mathrm{~h}$.

After U2OS cell seeding (at $1.5 \mathrm{~h}$ ), the mean numbers of adhering U2OS cells on the PMMA surface were $2.5 \times 10^{4}$, $8.2 \times 10^{4}$ and $17 \times 10^{4}$ cells $\mathrm{cm}^{-2}$ for the different seeding densities, with a mean area of the spread cells between $380 \mu \mathrm{m}^{2}$ and $540 \mu \mathrm{m}^{2}$ per cell. After $24 \mathrm{~h}$ of U2OS cell growth, S. epidermidis were allowed to adhere at a shear rate of $11 \mathrm{~s}^{-1}$ until levels of $10^{3}$ bacteria per $\mathrm{cm}^{2}$ were observed. The adhering U2OS cells were not affected during the initial adhesion of S. epidermidis.

After $24 \mathrm{~h}$ of simultaneous growth of U2OS cells and $S$. epidermidis, the number of adhering S. epidermidis was 
significantly higher $(P<0.01)$ on PMMA with the lower U2OS cell seeding density $\left(2.5 \times 10^{4}\right.$ cells $\mathrm{cm}^{-2}$ on average $)$ as compared to the number of adhering S. epidermidis on PMMA with higher U2OS cell-seeding densities (Fig. 1). There was no significant difference in number of adhering $S$. epidermidis cells on PMMA with U2OS cell seeding densities of $8.2 \times 10^{4}$, and $17 \times 10^{4}$ cells $\mathrm{cm}^{-2}$ (Fig. 2). From the phase-contrast images in Fig. 1, it is clear that bacteria do not form a contiguous biofilm, but are mainly adhering as single cells.

The adhering U2OS cells were immuno-cytochemically stained for CLSM analysis in order to determine their number and spread area after 48 h (Fig. 3). In Fig. 4, it can be seen that the percentage increase in number of adhering U2OS cells was significantly reduced due to the presence of adhering staphylococci in all cases as compared to the control, i.e. in the absence of adhering staphylococci $(P<0.01)$. The mean area per spread cell was approximately $1000 \mu \mathrm{m}^{2}$ at the two lower cell seeding densities, but at the highest cell seeding density of $17 \times 10^{4}$ cells $\mathrm{cm}^{-2}$, U2OS cells spread to only $460 \mu \mathrm{m}^{2}$ per cell, similar to the control (Fig. 5).

In the concept of the race for the surface, the total cell surface coverage of the substratum by host tissue cells is a determinant for the fate of an implant. The surface coverage of U2OS cells at $1.5 \mathrm{~h}$ after seeding and after $48 \mathrm{~h}$ of growth is shown in Fig. 6 . After $1.5 \mathrm{~h}$ of U2OS cell seeding, the mean surface coverages by U2OS cells on PMMA surfaces were $12 \%, 33 \%$ and $65 \%$ for seeding densities $2.5 \times 10^{4}, 8.2 \times 10^{4}$ and $17 \times 10^{4}$ cells $\mathrm{cm}^{-2}$, respectively. After $24 \mathrm{~h} \mathrm{U2OS}$ cell growth, a slight increase of $5-10 \%$ in surface coverage was observed (data not
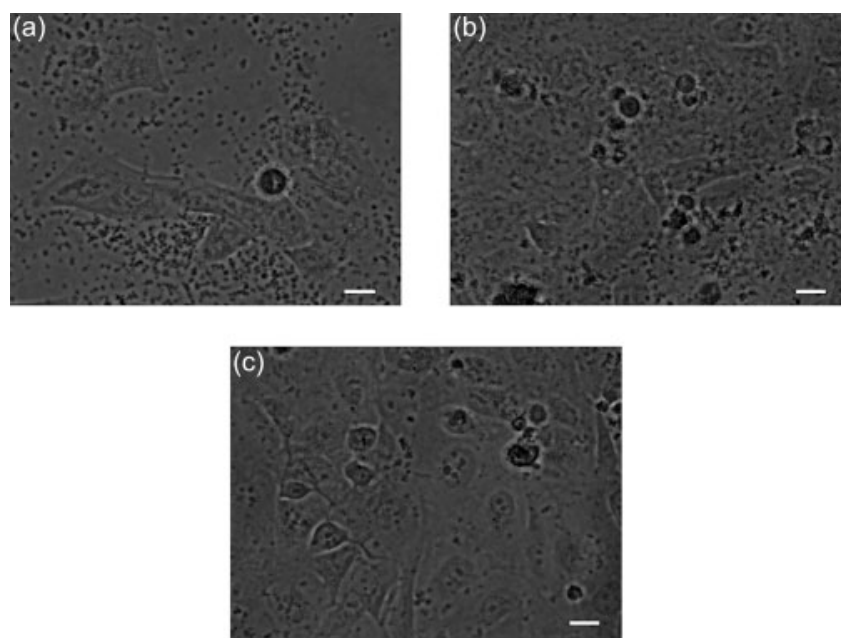

Fig. 1. Phase-contrast images of U2OS cells seeded to a density of (a) $2.5 \times 10^{4}$ cells cm $\mathrm{cm}^{-2}$, (b) $8.2 \times 10^{4}$ cells cm $^{-2}$ and (c) $17 \times 10^{4}$ cells $\mathrm{cm}^{-2}$ after $24 \mathrm{~h}$ of simultaneous growth in the presence of adhering S. epidermidis ATCC 35983 on PMMA. All images are taken at the same magnification. Scale bars, $10 \mu \mathrm{m}$.

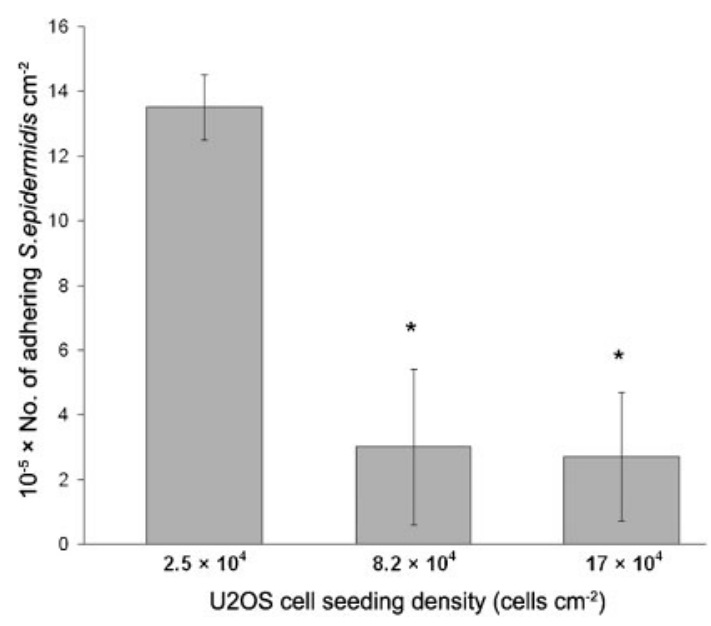

Fig. 2. Number of adhering S. epidermidis ATCC 35983 after $24 \mathrm{~h}$ of simultaneous growth of bacterial and U2OS cells on PMMA with different initial numbers of U2OS cells present. The $x$ axis represents the mean U2OS cell seeding densities. Error bars represent SD $(n=9)$. * Significant difference $(P<0.01)$ from the lowest U2OS cell seeding density $\left(2.5 \times 10^{4}\right.$ cells $\left.\mathrm{cm}^{-2}\right)$.

shown). After $48 \mathrm{~h}$ growth in the absence of S. epidermidis, a significant increase $(P<0.01)$ in surface coverage by adhering U2OS cells was observed compared to $1.5 \mathrm{~h}$. In the presence of $S$. epidermidis, a significant reduction $(P<0.01)$ in surface coverage by adhering U2OS cells was observed at the lowest cell seeding density $\left(2.5 \times 10^{4}\right.$ cells $\mathrm{cm}^{-2}$ ) as compared to the control, i.e. in the absence of adhering staphylococci. At the higher cell seeding densities, cell surface coverage was similar in the absence or presence of adhering staphylococci.

\section{DISCUSSION}

This paper presents the first experimental in vitro study on the race for the surface between bacteria and tissue cells on PMMA in a post-operative bacterial contamination model of implant surfaces. Below a threshold coverage of the substratum surface by adhering mammalian cells, contaminating S. epidermidis ATCC 35983 negatively affected mammalian cell growth, but once cell surface coverage exceeded a critical value, contaminating S. epidermidis ceased to negatively affect cell growth. The bacterial challenge chosen in the current experiments was low and is similar to peri-operative contamination levels (Kadurugamuwa et al., 2003; Fitzgerald, 1979). Kadurugamuwa et al. (2003) showed in a murine model that low doses of bacteria, introduced either peri-operatively or post-operatively, established a stable infection resembling clinical situations. Therefore, the bacterial challenge concentration used is considered relevant.

The current study was conducted with S. epidermidis. Clinically, S. epidermidis is one of the main causative 

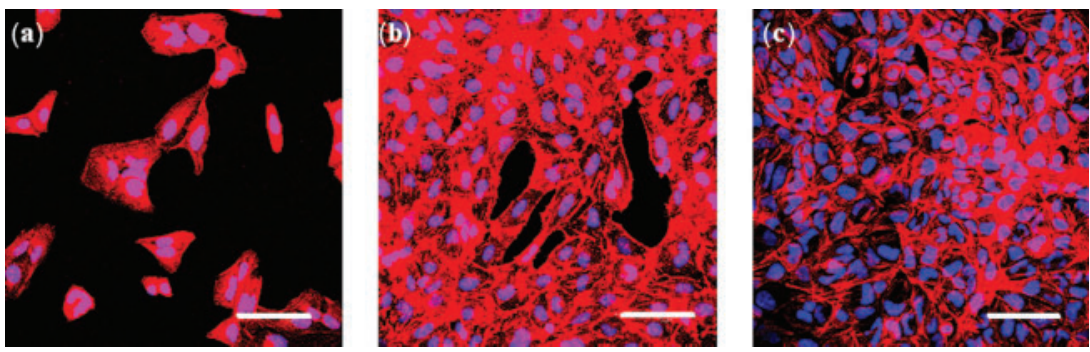

Fig. 3. CLSM images of U2OS cells seeded to a density of (a) $2.5 \times 10^{4}$ cells $\mathrm{cm}^{-2}$, (b) $8.2 \times 10^{4}$ cells $\mathrm{cm}^{-2}$ and (c) $17 \times 10^{4}$ cells $\mathrm{cm}^{-2}$ after $48 \mathrm{~h}$ growth in the presence of adhering S. epidermidis ATCC 35983 on PMMA. U2OS cells were stained with $5 \mathrm{ml}$ PBS containing $49 \mu \mathrm{l}$ DAPI and $2 \mu \mathrm{g} \mathrm{ml}{ }^{-1}$ TRITC-phalloidin. Scale bars, $75 \mu \mathrm{m}$.

organisms for BAI, in particular chronic prosthetic joint infections (Young \& Sugarman, 1988; Christensen et al., 1995). S. epidermidis can cause early post-operative contamination as long as wound closure is incomplete. Alternatively, late haematogenous spreading may occur from infections elsewhere in the body to an implant surface. Notorious in this respect are abscesses underneath the skin, developing, for instance, after minor injuries. Also, dental treatment is known to be a cause of post-operative contamination of implant surfaces, as even routine inspection of the dentition by a dentist or oral hygienist may give rise to bacteraemia (Okell \& Elliott, 1935; Ohara-Nemoto et al., 2008). BAI due to S. epidermidis is usually low grade, since the organism lacks the genes to produce the toxins and tissue-damaging exoenzymes that are produced by, for instance Staphylococcus aureus (Vuong \& Otto, 2002; Massey et al., 2006), another causative species of BAI (Young \& Sugarman, 1988; Christensen et al., 1995). S. aureus infections are therefore more aggressive than S. epidermidis ones, but at the same time are more readily noticed and treated. In a sense, this makes the low-grade BAI due to S. epidermidis more troublesome, which motivated our current choice of $S$.

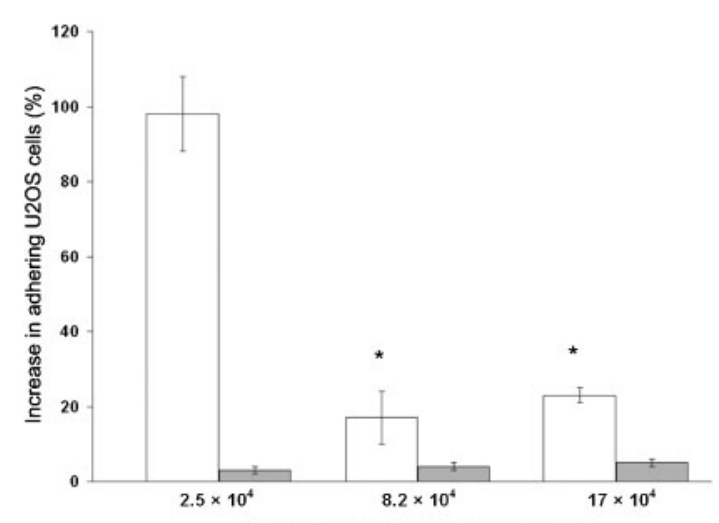

U2OS cell seeding density (cells $\mathrm{cm}^{-2}$ )

Fig. 4. Percentage increase in the number of adhering U2OS cells after $48 \mathrm{~h}$ growth with respect to their initial number immediately after seeding (at $1.5 \mathrm{~h}$ ) on PMMA in the absence (white bars) and presence (grey bars) of adhering S. epidermidis ATCC 35983. The $x$-axis represents the mean U2OS cell seeding densities. Error bars represent the SD $(n=9)$. *Significant difference $(P<0.01)$ from the lowest U2OS cell seeding density $\left(2.5 \times 10^{4}\right.$ cells $\left.\mathrm{cm}^{-2}\right)$. epidermidis in the set-up of our post-operative contamination model.

PMMA is well known for its use in ophthalmological, orthopaedic and dental applications. In orthopaedic applications, PMMA-based bone cements are extensively used for the fixation of total joint replacements, as the material supports cell adhesion and spreading (Lydon et al., 1985; van Wachem et al., 1985, 1987). In a perioperative contamination model, PMMA showed better tissue cell adhesion and spreading in the presence of adhering S. epidermidis than other commonly used biomaterials (Subbiahdoss et al., 2010).

In the concept of the race for the surface, complete surface coverage of a biomaterial in vivo by viable tissue cells, combined with functional host defence mechanisms, resists the negative consequences of bacterial contamination (Gristina, 1994). Rapid and complete surface coverage of mammalian cells restricts the biomaterial surface area available for bacterial adhesion and biofilm formation. Dexter et al. (2001) suggested that an optimal concentration of seeded 3T3 fibroblasts along with conditions suited to stimulate cell adhesion and surface coverage without stimulating bacterial adhesion could probably reduce infection. However, the consequence of the combined

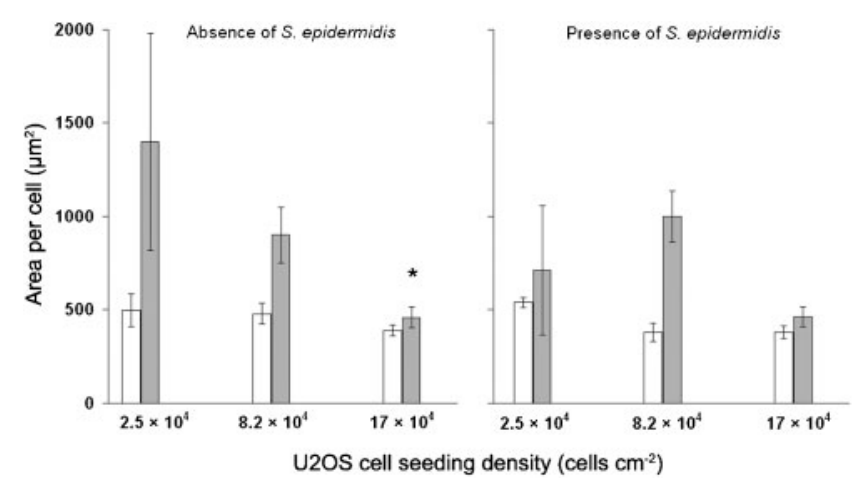

Fig. 5. Mean area per adhering U2OS cell immediately after seeding (at $1.5 \mathrm{~h}$ ) (white bars) and after $48 \mathrm{~h}$ (grey bars ) of growth on PMMA in the absence and presence of adhering $S$. epidermidis ATCC 35983. The $x$-axis represents the mean U2OS cell seeding densities. Error bars represent the standard deviations $(n=9)$. * Significant difference $(P<0.05)$ from the lowest U2OS cell seeding density $\left(2.5 \times 10^{4}\right.$ cells $\left.\mathrm{cm}^{-2}\right)$. 


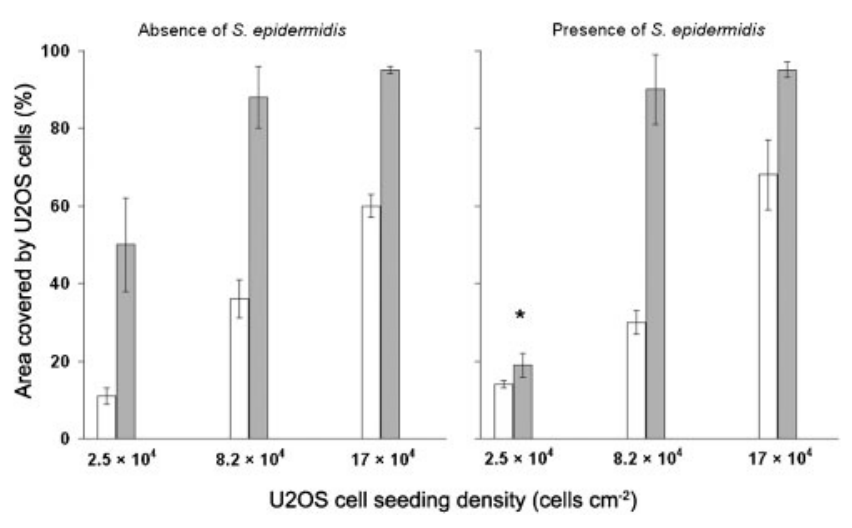

Fig. 6. Percentage surface coverage by adhering U2OS cells immediately after seeding for $1.5 \mathrm{~h}$ (white bars) and after $48 \mathrm{~h}$ (grey bars) of growth on PMMA in the absence and presence of adhering $S$. epidermidis ATCC 35983. The $x$-axis represents the mean U2OS cell seeding densities. Error bars represent the standard deviations $(n=9)$. *Significant difference $(P<0.01)$ from the control (absence of staphylococci).

presence of mammalian cells and bacteria on a surface was not monitored. In this study, the presence of $S$. epidermidis ATCC 35983 showed negative effects on cell surface coverage by U2OS cells at the lowest initial cell density $\left(2.5 \times 10^{4}\right.$ cells $\left.\mathrm{cm}^{-2}\right)$ as compared to cell surface coverage in the absence of adhering staphylococci. In contrast, surface coverage of U2OS cells after seeding higher initial cell densities was not influenced by the presence of $S$. epidermidis. This study therefore provides direct experimental evidence for the Gristina postulate (Gristina, 1994) that in vivo tissue integration protects implant surfaces against bacterial colonization. Moreover, our study defines a critical level of cell surface coverage that is needed in order to protect an implant surface against S. epidermidis biofilm formation. We anticipate that this critical cell surface coverage level will depend on the biomaterial surface characteristics as well as on the infecting strain. With this model system we present a tool to assess the 'race for the surface' and to compare different biomaterials, coatings and bacterial strains.

\section{Conclusions}

An in vitro method is presented to study the effects of postoperative bacterial contamination on the interaction of mammalian cells with biomaterial implants. A critical mammalian cell surface coverage was found, above which contaminating S. epidermidis ATCC 35983 no longer had a negative effect on mammalian cell growth. Thus, following the concept of the race for successful implantation of a biomaterial, survival of the implant will be more solidly assured if an implant is rapidly integrated by the tissue to levels above this critical cell surface coverage. This new method and the concept of a critical cell surface coverage will allow better evaluations of biomaterial coatings prior to animal experiments or human trials, than those based on separate studies of microbial adhesion to, or mammalian cell interactions with, such coatings.

\section{ACKNOWLEDGEMENTS}

This work was funded by the University Medical Centre Groningen.

\section{REFERENCES}

Christensen, G. D., Baldassarri, L. \& Simpson, W. A. (1995). Methods for studying microbial colonization of plastics. Methods Enzymol 253, 477-500.

Dexter, S. J., Pearson, R. G., Davies, M. C., Camara, M. \& Shakesheff, K. M. (2001). A comparison of the adhesion of mammalian cells and Staphylococcus epidermidis on fibronectin-modified polymer surfaces. J Biomed Mater Res 56, 222-227.

Fitzgerald, R. H. (1979). Microbiologic environment of the conventional operating-room. Arch Surg 114, 772-775.

Gristina, A. G. (1987). Biomaterial-centered infection: microbial adhesion versus tissue integration. Science 237, 1588-1595.

Gristina, A. G. (1994). Implant failure and the immune-incompetent fibro-inflammatory zone. Clin Orthop Relat Res 298, 106-118.

Gristina, A. G., Rovere, G. D., Shoji, H. \& Nicastro, J. F. (1976). An in vitro study of bacterial response to inert and reactive metals and to methyl methacrylate. J Biomed Mater Res 10, 273-281.

Gristina, A. G., Naylor, P. \& Myrvik, Q. (1988). Infections from biomaterials and implants: a race for the surface. Med Prog Technol 14, 205-224.

Gristina, A. G., Naylor, P. T. \& Myrvik, Q. N. (1990). Musculoskeletal infection, microbial adhesion and antibiotic resistance. Infect Dis Clin North Am 4, 391-408.

Habash, M. \& Reid, G. (1999). Microbial biofilms: their development and significance for medical device-related infections. $J$ Clin Pharmacol 39, 887-898.

Kadurugamuwa, J. L., Sin, L., Albert, E., Yu, J., Francis, K., DeBoer, M., Rubin, M., Kawahara, C. B., Parr, T. R. \& Contag, P. R. (2003). Direct continuous method for monitoring biofilm infection in a mouse model. Infect Immun 71, 882-890.

Lydon, M. J., Minett, T. W. \& Tighe, B. J. (1985). Cellular interactions with synthetic-polymer surfaces in culture. Biomaterials 6, 396402.

Massey, R. C., Horsburgh, M. J., Lina, G., Hook, M. \& Recker, M. (2006). Opinion - The evolution and maintenance of virulence in Staphylococcus aureus: a role for host-to-host transmission? Nat Rev Microbiol 4, 953-958.

Ohara-Nemoto, Y., Haraga, H., Kimura, S. \& Nemoto, T. K. (2008). Occurrence of staphylococci in the oral cavities of healthy adults and nasal-oral trafficking of the bacteria. J Med Microbiol 57, 9599.

Okell, C. C. \& Elliott, C. D. (1935). Bacteriaemia and oral sepsis with special reference to the etiology of subacute endocarditis. Lancet 2, 869-875.

Proctor, R. A., Von Eiff, C., Kahl, B. C., Becker, K., McNamara, P., Herrmann, M. \& Peters, G. (2006). Small colony variants: a pathogenic form of bacteria that facilitates persistent and recurrent infections. Nat Rev Microbiol 4, 295-305.

Singh, R., Ray, P., Das, A. \& Sharma, M. (2009). Role of persisters and small-colony variants in antibiotic resistance of planktonic and 
biofilm-associated Staphylococcus aureus: an in vitro study. J Med Microbiol 58, 1067-1073.

Subbiahdoss, G., Kuijer, R., Grijpma, D. W., Van der Mei, H. C. \& Busscher, H. J. (2009). Microbial biofilm growth vs. tissue integration: "the race for the surface" experimentally studied. Acta Biomater 5, 1399-1404.

Subbiahdoss, G., Grijpma, D. W., Van der Mei, H. C., Busscher, H. J. \& Kuijer, R. (2010). Microbial biofilm growth vs. tissue integration on biomaterials with different wettabilities and a polymer-brush coating. J Biomed Mater Res A 9, 533-538.

van Wachem, P. B., Beugeling, T., Feijen, J., Bantjes, A., Detmers, J. P. \& Vanaken, W. G. (1985). Interaction of cultured human endothelial cells with polymeric surfaces of different wettabilities. Biomaterials $\mathbf{6}$, 403-408.

van Wachem, P. B., Hogt, A. H., Beugeling, T., Feijen, J., Bantjes, A., Detmers, J. P. \& Vanaken, W. G. (1987). Adhesion of cultured human endothelial cells onto methacrylate polymers with varying surface wettability and charge. Biomaterials 8, 323-328.

Vuong, C. \& Otto, M. (2002). Staphylococcus epidermidis infections. Microbes Infect 4, 481-489.

Young, E. J. \& Sugarman, B. (1988). Infections in prosthetic devices. Surg Clin North Am 68, 167-180.

Edited by: T. J. Mitchell 